\title{
Creencias y actitudes hacia las variedades cultas del español actual: el proyecto PRECAVES XXI
}

\author{
Ana M. Cestero* \\ Universidad de Alcalá, España \\ Florentino Paredes** \\ Universidad de Alcalá, España
}

\begin{abstract}
Resumen
Describir la variación lingüística y explicar la razón de su existencia son dos de los principales objetivos de la sociolingüística, para cuyo logro propone analizar las creencias y actitudes de los individuos hacia los usos lingüísticos y la percepción de las variedades lingüísticas y los comportamientos hacia ellas (López Morales 1989, Moreno Fernández 2012, Martín Butragueño 2014). Con objeto de aportar datos empíricos relativos a estas dimensiones, nació en 2013 el Proyecto para el estudio de creencias y actitudes hacia variedades del español en el siglo XXI (PRECAVES-XXI) (Cestero y Paredes 2015a), un proyecto panhispánico en el que participan coordinadamente equipos de gran parte del dominio lingüístico
\end{abstract}

* Para correspondencia, dirigirse a: Ana M. Cestero (anam.cestero@uah.es), Universidad de Alcalá, España. Colegio San José de Caracciolos C/ Trinidad 5, 28801 - Alcalá de Henares (Madrid - España). Teléfono: +34 918854422.

** Para correspondencia, dirigirse a: Florentino Paredes (florentino.paredes@uah.es), Universidad de Alcalá. Colegio San José de Caracciolos C/ Trinidad 5, 28801 - Alcalá de Henares (Madrid - España). Teléfono: +34 918854481. 
de la lengua española con objeto de investigar la percepción de las variedades cultas del español mediante una encuesta basada fundamentalmente en la técnica de pares falsos o matched guise. Como marco teórico y metodológico del proyecto $-\mathrm{y}$, por tanto, de los estudios que conforman el volumen monográfico-, en este artículo se presenta la fundamentación teórica que sostiene el proyecto PRECAVES XXI y los procedimientos metodológicos ideados y utilizados para llevar a cabo la investigación. Se presenta, además, la configuración del número monográfico, avanzando información comparativa de las zonas estudiadas.

Palabras clave: creencias lingüísticas, actitudes lingüísticas, percepciones, variedades del español, cuestionario, PRECAVES XXI.

BELIEFS AND ATTITUDES TOWARDS EDUCATED VARIETIES OF CONTEMPorary SPANISH: the PRECAVES XXI Project

\section{Abstract}

The description of linguistic variety and the explanation of why it exists are two of the main goals of sociolinguistics. To achieve those goals sociolinguistics sets itself the task of analysing the beliefs and attitudes people have towards language uses as well as how linguistic varieties are perceived and reacted to. In 2013, the Proyecto para el estudio de creencias y actitudes hacia variedades del español en el siglo XXI (PRECAVES XXI [Project for the study of beliefs and attitudes regarding varieties of Spanish in the 21st century]) came into being with a view to gathering empirical data related to those issues. It is a pan-Hispanic project in which coordinated teams from all over the world take part in researching the perception of educated varieties of Spanish with the aid of a survey based mainly on the matched guise technique. By way of theoretical and methodological framework for the project and, therefore, of the studies comprising this monograph, this article introduces the theoretical grounding of the PRECAVES XXI project and the methodological procedures devised and employed to carry out the research. It also introduces the plan of the monographic volume and offers some preliminary comparison of the information gathered in the areas studied.

Keywords: linguistic beliefs, linguistic attitudes, perceptions, varieties of Spanish, Castilian Spanish, questionnaire, PRECAVES XXI.

Recibido: 30/01/2018 Aceptado: 29/06/2018 


\section{CREENCIAS Y ACTITUDES SOCIOLINGÜÍSTICAS: ALGUNAS CONSIDERACIONES TEÓRICAS ${ }^{1}$}

La sociolingüística tiene como objetivo básico, desde su nacimiento, la descripción de la lengua en uso y, en su consecución, ha aportado datos de gran interés con respecto no solo al uso real de la lengua y a la incidencia que sobre él tiene la caracterización social del hablante y el contexto, sino, además, a las razones por las que se da y se mantiene la variación. La causa última de la variación lingüística y sociolingüística, así como la de la conducta humana, como apuntaron López Morales (1989) y Moreno Fernández (2005), entre otros, hay que buscarla en las creencias y actitudes de los hablantes, que estigmatizan o conceden estatus tanto a los usos lingüísticos concretos como a las variedades de una lengua o a lenguas en contacto; sin embargo, y a pesar de la gran importancia que tienen, no se ha priorizado su análisis, por lo que son pocos los estudios llevados a cabo y, por tanto, insuficientes los conocimientos que tenemos sobre el funcionamiento y las repercusiones de las percepciones sociolingüísticas y comunicativas.

Las primeras investigaciones sobre creencias y actitudes se realizaron en el seno de la psicología social, desde la consideración de que son reflejo de percepciones y actitudes psicosociales, y constituyen el marco teórico mediato de su estudio actual. A pesar de que hace ya muchos años que los psicólogos sociales y los sociolingüistas se interesan por ellas ${ }^{2}$, no tenemos un concepto único de lo que se considera actitud ni de los componentes que la integran. Hasta ahora, el estudio de las actitudes sociolingüísticas se ha enfocado desde dos perspectivas diferentes: la mentalista, que la considera un estado mental producido por estímulos determinados que

\footnotetext{
1 Este artículo se inscribe dentro de las actividades científicas de los proyectos de investigación La población migrante de la comunidad de Madrid: estudio multidisciplinar y herramientas para la integración sociolingüística (IN.MIGRA2-CM; ref. H2015/ HUM3404) -financiado por la Comunidad de Madrid y el Fondo Social Europeo-, y Estudio complementario de los patrones sociolingüísticos y procesos de integración sociolingüística en Madrid (ECOPASIS_MAD; ref. FFI2015-68171-C5-4-P), -financiado por el Ministerio de Economía y Competitividad-.

2 Véanse los trabajos pioneros, ya clásicos, de Allport (1935), Lambert et al. (1960) o Lambert (1964 y 1967), y de Agueyisi y Fishman (1970), Shuy y Fasold (1973), Williams (1973 y 1974), Cooper y Fishman (1974 y 1975) y Giles y Ryan (1982). No podemos olvidar que se atiende a las creencias y actitudes, también, desde la corriente conocida como dialectología perceptiva; pueden consultarse al respecto los trabajos de Preston $(1989,1999,2003)$ y los incluidos en Prikhodkine y Preston (2015), muy influyentes en las investigaciones actuales; véase también Moreno y Moreno (2004).
} 
provocan respuestas (Allport 1935, Williams 1974, Gardner 1982 y 1985, Ajzen 1988), y la conductista, que la concibe como la acción observable como consecuencia de la reacción a estímulos diversos (Osgood et al. 1957, Fishbein 1965). Las concepciones subyacentes en las dos perspectivas conducen a la falta de definición precisa de lo que es la actitud misma. De hecho, más que concretar el concepto, los investigadores se han ocupado de establecer modelos componenciales diversos, que coinciden en considerar la actitud como un constructo que resulta de la combinación de diferentes dimensiones - cognoscitiva, afectiva y conductual-, y que la relacionan con las creencias en diferentes niveles.

Los autores de este trabajo consideramos la actitud, siguiendo la propuesta de López Morales (1989: 235), como la acción o reacción misma-conducta-, la aceptación o el rechazo de un hecho lingüístico $-\mathrm{y}$, por tanto, el uso o desuso de una variante, de una variedad o de una lengua-, que se produce por las creencias, favorables o adversas, hacia el hecho en cuestión; tales creencias provienen de los conocimientos lingüísticos y sociolingüísticos del hablante, es decir, de su conciencia sociolingüística -dimensión cognoscitiva- o de percepciones y consideraciones relacionadas con la subjetividad y la emoción -dimensión afectiva-propias y de su comunidad de habla. Con base en esta perspectiva, el engranaje sociolingüístico puede explicarse de la manera que sigue: el conocimiento del funcionamiento del uso lingüístico, así como las percepciones afectivas hacia él por parte de los miembros de una comunidad, produce ciertas creencias sobre ese uso, que, si son positivas, le confieren estatus y pueden provocar actitudes positivas en el individuo, quien, por tanto, lo acepta y lo emplea, pero, si son negativas, lo estigmatizan, dando como resultado la aparición de actitudes negativas que impiden que los miembros de la comunidad lo hagan suyo. Se representa esquemáticamente en la figura 1 . 


\section{FENÓMENOS LINGÜÍSTICOS}

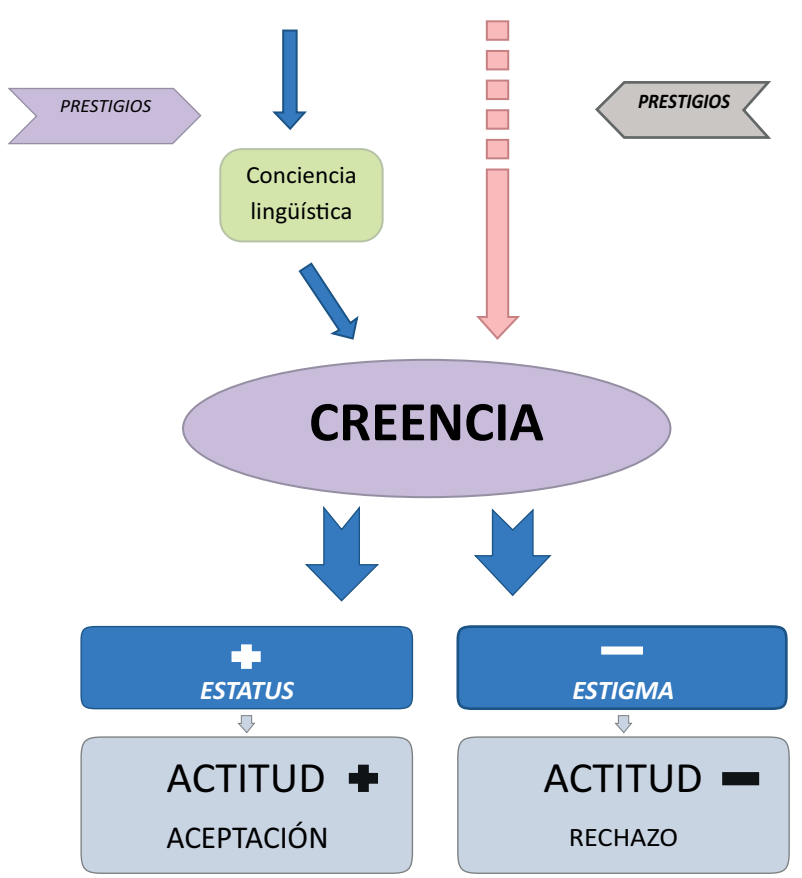

Figura 1. Engranaje sociolingüístico

(Fuente: elaboración propia a partir de López Morales 1989: 235)

Esta concepción, fundamentalmente ecléctica, nos permite el estudio empírico de las actitudes sociolingüísticas a partir de las percepciones y creencias de los individuos hacia dimensiones que tienen que ver, por un lado, con su conocimiento - componente cognoscitivo: conciencia sociolingüística basada en prestigios abiertos, sociales y lingüísticos- y, por otro, con su afectividad-componente afectivo: sentimientos provenientes de prestigios psicosociales abiertos o encubiertos, que se relacionan con gustos, identidad, solidaridad, lealtad, etc.-, mediante un procedimiento metodológico basado en valoraciones directas e indirectas, que nos informan de la predisposición del hablante a utilizar o no utilizar el fenómeno lingüístico examinado, ya se trate de una variante de una variable, una variedad lingüística o una lengua en situación de contacto con otra u otras, o de la predisposición del hablante a enseñar o aprender una variedad o una lengua segunda o extranjera. 
Las dimensiones y las consideraciones apuntadas han configurado el Proyecto para el estudio de creencias y actitudes hacia variedades del español en el siglo XXI (PRECAVES XXI), con el que se pretende conocer las percepciones de los sujetos hacia su propia variedad y otras variedades cultas del español (y sus usos sociolingüísticos), analizándolas en relación con la caracterización social y ocupacional de los individuos, y documentar, a través de ellas, creencias y actitudes psicosociales y sociolingüísticas. Nos mueve el deseo de aportar conocimiento a un tema cuya gran importancia se había reconocido ya a mediados del siglo XX y que, desde entonces, no ha dejado de atenderse, si bien no ha llegado a tener aún un cuerpo teórico y metodológico homogéneo, ni se ha conseguido el grado de profundización deseable. Los trabajos realizados hasta el momento se han centrado en conocer las percepciones de los individuos hacia usos sociolingüísticos concretos y, especialmente, hacia las lenguas utilizadas en comunidades bilingües o plurilingües ${ }^{3}$; son menos los estudios que se centran en las percepciones y creencias de distintos colectivos o ciertas comunidades hacia las variedades de una misma lengua, así como de las actitudes que provocan $^{4}, \mathrm{y}$ de su incidencia en ámbitos concretos de gran desarrollo en la actualidad, tales como la enseñanza y adquisición de lenguas segundas y extranjeras ${ }^{5}$.

3 Como muestra, pueden consultarse los trabajos de Agueyisi y Fishman (1970), Cooper y Fishman (1974, (eds.) 1974 y (eds.) 1975) o Giles y Ryan (1982), y, con respecto al español, el trabajo pionero de Alvar López (1986a) y el de Lope Blanch (1986), así como el estudio sobre el uso de lenguas cooficiales en Valencia de Gómez Molina (1998 y 2002) y de sus colaboradores (Buzón, Gómez y Gómez 2017). Para la convivencia del español con otras lenguas en diferentes comunidades, es conveniente releer las investigaciones de Rubín (1968), de la Zerda y Hopper (1975), Corvalán y de Granda (1982), Quilis (1983), Pitarch (1983), Gimeno Menéndez (1986), Etxebarria Arostegui (1995) y Lasagabaster (2007).

4 Para el caso de variedades del español, pueden consultarse los trabajos de Alvar López (1972, 1981, 1983, 1986b), Cohen (1974), de la Zerda y Hopper (1975), Alvar y Quilis (1984), Lope Blanch (1968, 1972a, 1972b, 1986), Ortega Ojeda (1981), López Morales (1979, 1983, 2001), Castellanos (1980), Lamíquiz y Carbonero (1987), Martínez y Moya (2000), Moreno Fernández (1992) o Martín Zorraquino (1995) y, más recientemente, el de Moreno Fernández (2009) o el de Quintanilla (2012). Hemos de destacar, de manera especial, los trabajos fruto del proyecto LIAS (Linguistic Identity and Attitudes in Spanish-speaking Latin America), dirigido por Miguel Ángel Quesada y Beatriz Chiquito, del que ya pueden verse resultados de gran interés en Chiquito y Quesada (2014).

5 Las investigaciones acerca de las actitudes en la adquisición y enseñanza de español como lengua extranjera o segunda se están desarrollando en dos ámbitos distintos: la enseñanza de lenguas segundas y extranjeras y la inmigración. En relación con el primero, aunque se trabaja, a su vez, desde perspectivas diferentes, se pueden destacar los estudios que parten de las investigaciones de Lambert y sus colaboradores (1968) y se centran en actitudes sociolingüísticas de los aprendices de español que tienen una repercusión importante en su 
Los avances teóricos y metodológicos de las investigaciones llevadas a cabo están en la base de nuestro Proyecto, con el que, como se ha mencionado con anterioridad, nos hemos propuesto conocer las creencias y actitudes de distintos grupos de individuos hacia las variedades normativas del español, partiendo de las que tienen hacia su propia variedad. Para ello, ideamos una metodología y propusimos su utilización a diversos equipos de investigadores de los dos lados del Atlántico, configurando un proyecto de grandes dimensiones. En la actualidad, integran el equipo de investigación Ana M. Cestero Mancera y Florentino Paredes García (coordinadores, Universidad de Alcalá-España), Antonio Ávila e Inmaculada Santos (Universidad de Málaga-España), José Ramón Gómez Molina y Cristina Villalba (Universidad de Valencia-España), Ana M. González Marfud (Universidad de La Habana-Cuba), Claudia González Rátiva y Diana MuñozBuiles (Universidad de Antioquia-Colombia), Silvana Guerrero y Abelardo San Martín (Universidad de Chile-Chile), Claudia Borzi y Sofía Gutiérrez Böhmer (Universidad de Buenos Aires-Argentina), Clara E. Hernández Cabrera y Marta Samper Hernández (Universidad de Las Palmas de Gran Canaria-España), Cristina Illamola (Universidad de Barcelona-España), Irania Malaver (Universidad Central de Venezuela-Venezuela), Antonio Manjón-Cabeza Cruz y Marcin Sozinski (Universidad de Granada-España), Beatriz Méndez Guerrero (Universidad Autónoma de Madrid-España), Dinorah Pesqueira (Tecnológico de Monterrey-México) y Juana Santana Marrero (Universidad de Sevilla-España).

La investigación coordinada ha comenzado a dar ya frutos de gran interés, recogidos, en parte, en este monográfico. Presentamos, a continuación, los fundamentos metodológicos de PRECAVES XXI y concluimos el artículo con un avance de lo que podrán encontrar en los diversos trabajos que componen el volumen monográfico.

proceso de aprendizaje de la lengua extranjera; véase, como ejemplo, el estudio de Cobo de Gambier (2011). Del segundo ámbito consideramos conveniente mencionar los estudios de Sanz Huéscar $(2008,2010)$ o los de Sancho Pascual (2014). 


\section{METODOLOGÍA DE LA INVESTIGACIÓN EN PRECAVES XXI}

A pesar de la gran importancia que tienen las creencias y actitudes en ámbitos diversos relacionados con la variación lingüística (uso de variantes de un fenómeno variable y cambio lingüístico, uso de variedades de una lengua y pervivencia de las mismas y uso de lenguas diferentes en contextos bilingües y plurilingües, incluida la adquisición y enseñanza de lenguas segundas o extranjeras), no contamos aún con un cuerpo teórico unánime y plenamente establecido ni con una metodología básica que permita su investigación de manera sistemática y en profundidad. La razón, bien conocida por todos, es la gran dificultad que entraña su estudio, ya que se pretende conocer la predisposición y el comportamiento del individuo a partir de sus percepciones y valoraciones -creencias-, provenientes tanto del conocimiento que tiene de cómo funcionan los hechos lingüísticos (conciencia sociolingüística), como de la afectividad (posición subjetiva que deriva de gustos, emociones o sentimientos), lo que implica atender realidades no materiales.

La identificación y medición de las actitudes es una labor compleja, y la metodología que se emplee para ello dependerá, en última instancia, de la posición que se adopte con respecto a la concepción misma de actitud. En el Proyecto para el estudio de creencias y actitudes hacia variedades del español en el siglo XXI, la posición de base es ecléctica, como ya se ha mencionado; se considera que es posible conocer actitudes de los individuos, en el estudio que nos ocupa hacia las variedades cultas del español, a partir de las valoraciones que realizan, asumiendo, como indican claramente Buzón, Gómez y Gómez (2017: 65), que la percepción de un estímulo (fragmento discursivo en nuestro caso) "pone en marcha una reacción evaluativa (favorable/desfavorable) en un contexto de consideraciones y conocimientos compartidos (social), resultado de los procesos cognoscitivo y afectivo (individual)". Tales presupuestos nos llevaron a diseñar una metodología que aúna técnicas directas e indirectas de recogida de datos ${ }^{6}$, teniendo en cuenta los avances al respecto de investigaciones previas, y que presentamos detalladamente a continuación.

6 También lo hicieron Gómez Molina y sus colaboradores en el estudio sobre actitudes lingüísticas en Valencia (Gómez Molina 1998 y 2002; Buzón, Gómez y Gómez 2017). 


\subsection{LA MEDICIÓN DE CREENCIAS Y ACTITUDES: RECOGIDA DE MATERIALES}

Para desarrollar PRECAVES XXI, preparamos una prueba que, partiendo de la técnica de pares falsos o máscaras ${ }^{7}$, permite obtener, de forma directa y de forma indirecta, información sobre la valoración que los individuos hacen de las variedades cultas del español y, consecuentemente, sobre sus actitudes hacia ellas. Nuestra pretensión es conseguir datos y estudiar todo el dominio de habla hispana por zonas generales, estableciendo como tales las ocho correspondientes a las consideradas como de influencia de variedades cultas del español, a saber, centro y norte de España, sur de España, Canarias, México y Centroamérica, Caribe, Andes, Chile y Río de la Plata (Moreno Fernández 1993, 2000 y 2009; Moreno y Otero 2007).

La recogida de material se realiza mediante entrevista directa a un número indeterminado de informantes a la vez, siguiendo siempre un mismo procedimiento, que se desarrolla a través de una aplicación informática creada para tal fin (www.variedadesdelespanol.es) ${ }^{8}$. Los pasos que se dan son los siguientes:

1) Se informa a los sujetos del procedimiento de encuesta que se va a seguir, a saber:

1. Entrar en la plataforma y comenzar la encuesta cumplimentando el apartado de datos individuales del cuestionario.

2. Escuchar una grabación con las voces de diferentes hombres o mujeres hablantes de español.

3. Oír una a una 16 grabaciones, que no tienen por qué ser de personas diferentes o de distintos países, e ir completando el cuestionario que se proporciona sobre cada una de ellas.

Se da a cada informante una clave personal, que sirve para entrar en la encuesta y como identificador de sujeto, y se explica la forma de acceso.

2) Los informantes acceden a la explicación breve inicial y rellenan, para empezar, los datos personales y sociogeolectales que se recogen con el cuestionario.

7 Dicha técnica, como es bien sabido, fue empleada por Lambert y sus colaboradores $(1960,1967)$ en diversos estudios pioneros realizados durante los años sesenta, y sigue considerándose la mejor forma de obtener datos para estudiar las creencias y actitudes lingüísticas.

${ }_{8}$ También es posible recoger material, con un procedimiento similar, apoyándose en una presentación con un documento en formato PowerPoint ${ }^{\circ}$ proyectado con los audios insertados. 


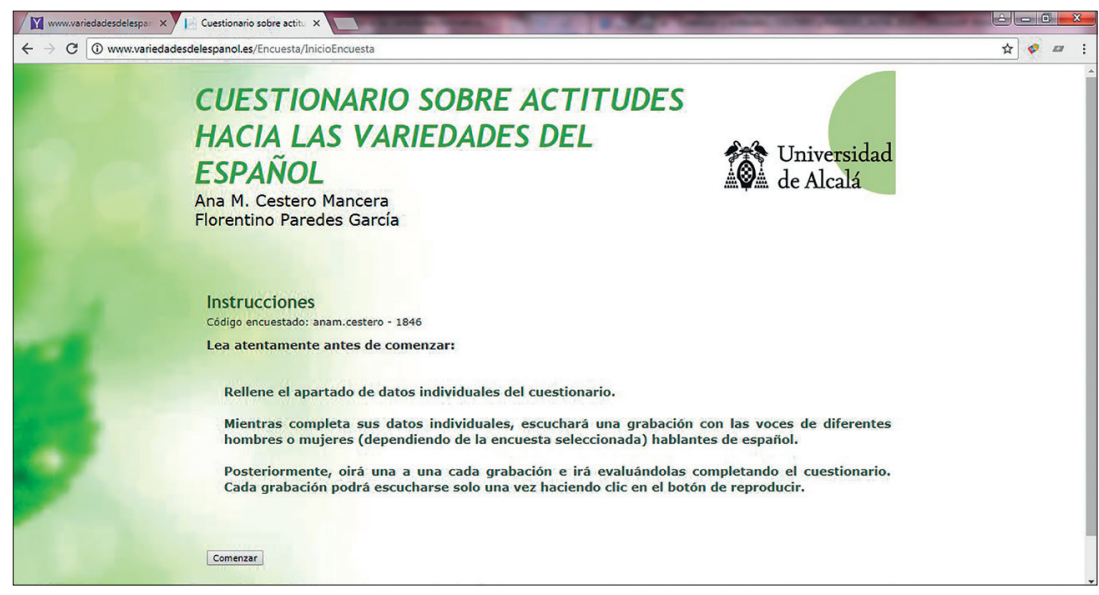

Figura 2. Explicación del Cuestionario sobre actitudes hacia las variedades del español

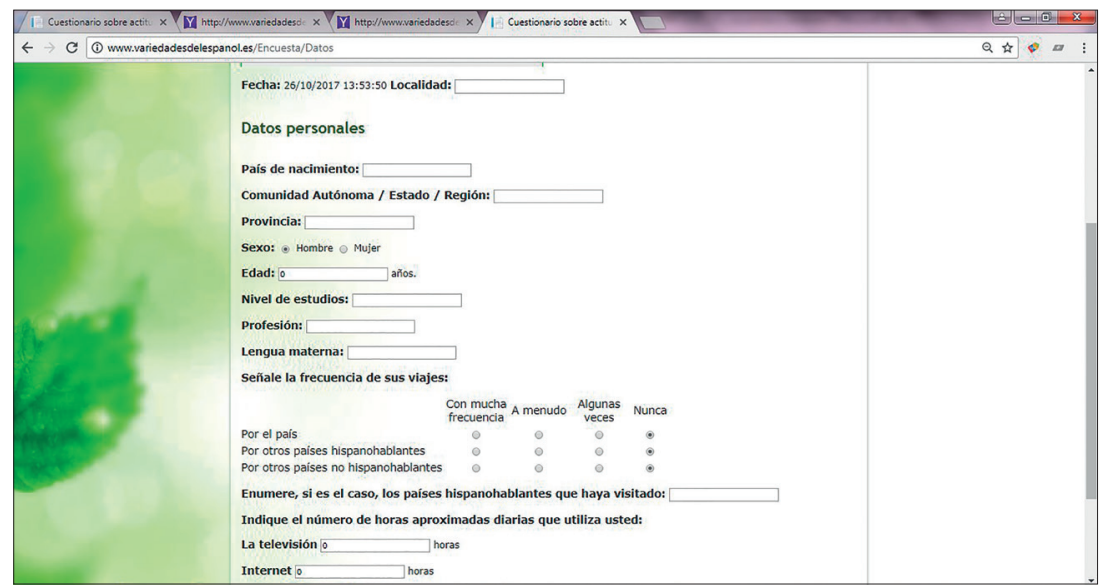

Figura 3. Datos personales y sociogeolectales

3) Se activa una audición compuesta por fragmentos de las 8 grabaciones de discurso oral que se van a utilizar. Con ello se pretende que el informante tenga una primera aproximación a las diferentes variedades que va a evaluar. 


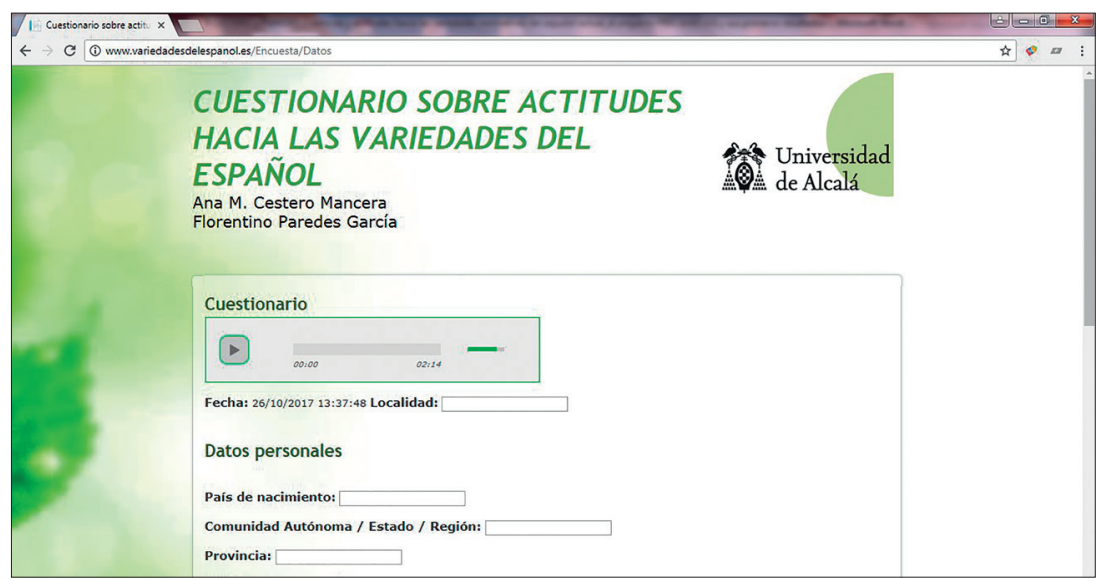

Figura 4. Audición con fragmentos de las 8 grabaciones de discurso oral

4) Audiciones y cumplimentación de cuestionarios. Se van poniendo, sucesivamente, las grabaciones, y, una vez que se han escuchado, los informantes contestan el cuestionario correspondiente a la grabación; se procede de la misma manera hasta llegar a la grabación 16. Las grabaciones de los diferentes hablantes están mezcladas y se alterna discurso oral y lectura, como explicaremos en breve. A partir de la segunda audición, se puede ir rellenando el cuestionario a la vez que se escucha la grabación (no es necesario esperar a que acabe cada una de ellas).

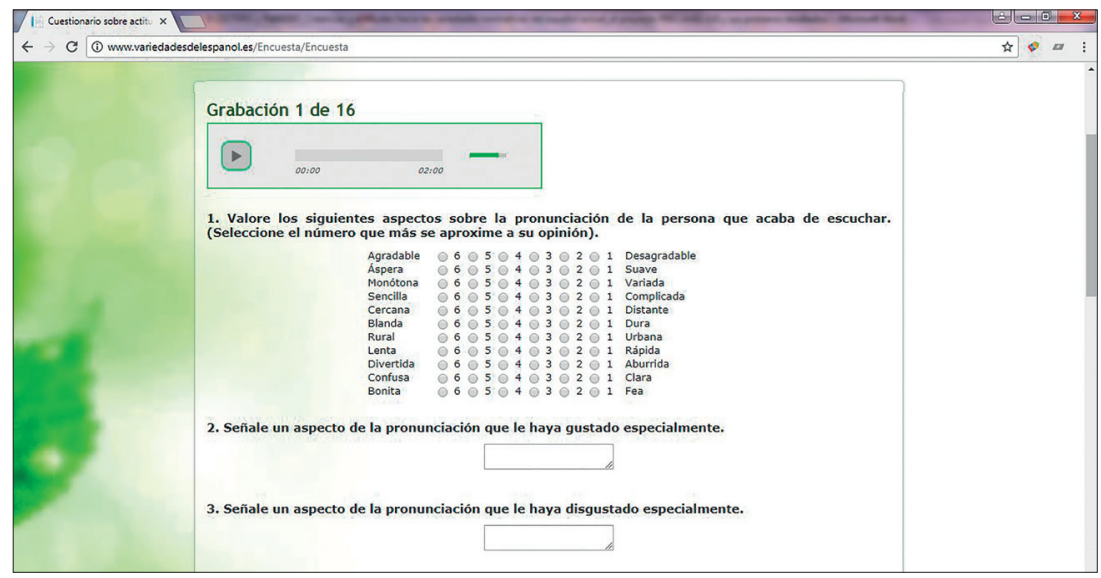

Figura 5. Audiciones y cumplimentación de cuestionarios 
El programa creado para la aplicación informática va ofreciendo las pantallas de manera sucesiva, con explicaciones de las actuaciones que hay que efectuar. Es una forma de recogida de datos muy productiva, pues, además de facilitar la codificación de respuestas, permite que no sea necesario hacer la encuesta de una sola vez: el informante puede conectarse en el momento que quiera y desde el lugar que estime oportuno, y escuchar las audiciones que desee, siempre en orden, y responder a lo que se plantea sobre ellas.

La duración de la encuesta completa es de alrededor de una hora y en ella se trabaja únicamente con audiciones solo de hombres o solo de mujeres, con objeto de controlar que el timbre masculino o femenino de la voz evaluada no interfiera en las valoraciones.

\subsubsection{La encuesta}

La encuesta diseñada para el estudio de las creencias y actitudes hacia las variedades normativas del español en el siglo XXI, como se puede deducir de la organización de recogida de material presentada previamente, se estructura en tres partes: recogida de datos personales y sociogeográficos, escucha de grabaciones y realización de un cuestionario.

\subsubsection{Datos personales y sociogeográficos}

La primera parte de la encuesta está dedicada a recabar información acerca de aspectos personales del informante, así como de su perfil social y geolectal. Comienza, como se ha podido comprobar en la figura 3, por constatar la fecha de realización y la localidad de recogida de material. Al obtener las claves de acceso para los informantes, ya se establece el colectivo al que pertenece.

Los datos personales a los que se atiende, por su posible incidencia en las creencias y actitudes sociolingüísticas, son sexo, edad, nivel de estudios, profesión y lengua materna. Para el establecimiento de grupos sociales, seguimos los criterios de intervalos establecidos en el Proyecto para el estudio sociolingüístico del español de España y América (PRESEEA) (Moreno Fernández 1996, PRESEEA 2008), de manera que se distinguen las siguientes variables y variantes independientes:

- Sexo: hombre y mujer.

- Edad: menos de 20 años, de 20 a 34 años, de 35 a 54 años y más de 55 años. 
- Nivel de estudios: sin estudios o con estudios primarios, con estudios secundarios, con estudios universitarios ${ }^{9}$.

- Profesión: obreros sin calificar, obreros con cualificación, empleados medios, pequeños empresarios autónomos, medianos empresarios, profesiones liberales (se incluyen aquí los docentes), altos directivos y grandes empresarios, sin profesión (estudiantes y amas de casa).

- Lengua materna. Se distingue entre español como lengua materna y otras lenguas, y se anota de qué lengua se trata, en caso de no ser el español, para comprobar la incidencia en las creencias y actitudes de proximidad lingüística y cultural.

Los datos sociogeográficos que se recogen, también por su implicación en las valoraciones y comportamientos del individuo, son el país de nacimiento y los países hispanohablantes que haya visitado. En relación con ellos, tenemos en cuenta las siguientes variables y variantes independientes:

- País de nacimiento. Se anota el país de nacimiento, que se subclasifica, además, en atención a si se trata de un país hispanohablante o no.

- Contacto con otras variedades del español. Se constata si el informante ha visitado países hispanohablantes diferentes al de nacimiento.

- Países hispanohablantes visitados. Se le pide al informante que indique qué países hispanohablantes ha visitado y, para el análisis, se tiene en cuenta el número de países en los que ha estado: uno, entre dos y cuatro y más de cuatro.

- Uso de internet y de la televisión. Se le pregunta por el número de horas que usa diariamente estos medios con objeto de conocer la posible influencia de la actitud hacia las variedades según el mayor o menor contacto con estos medios de comunicación e información.

\subsubsection{Escucha de grabaciones}

El procedimiento ideado para la recogida de datos y la medición de actitudes, como se ha mencionado con anterioridad, parte de la técnica de pares falsos o de máscaras, con la adaptación requerida para cumplir los objetivos propuestos.

\footnotetext{
Se considera que un individuo pertenece a un nivel de estudios siempre que tenga el primer curso completo de dicho nivel; así, por ejemplo, los estudiantes que cursan el primer año de un grado universitario pertenecerán al grupo de estudios secundarios y no al de universitarios.
} 
La recogida de material para estudio se basa en la escucha de 16 grabaciones, 8 procedentes de discurso oral y 8 de lectura de texto escrito, pertenecientes a hombres adultos o mujeres adultas de entre 34 y 54 años, con nivel de estudios superior. Hemos obtenido grabaciones de un hombre y de una mujer cultos de cada una de las variedades normativas con las que trabajamos (castellana, andaluza, canaria, mexicana y centroamericana, caribeña, andina, chilena y rioplatense $)^{10}$. Así, en total, disponemos de 2 grabaciones de voz de 16 hablantes, una en la que hablan durante unos dos minutos sobre el problema que ocasiona el tráfico en las grandes ciudades ${ }^{11}$, con control temático por tanto, y otra en la que leen durante un minuto un texto escrito sobre la vivienda que reproducimos a continuación:

La vivienda es algo más que una simple necesidad básica. De hecho, la casa que elegimos para vivir acaba siendo un reflejo de nuestra personalidad, de nuestra forma de entender la vida y de vivirla. La vivienda nos da cobijo, nos protege de las agresiones del entorno y facilita la comunicación dentro de la familia. Por todo ello, es normal que se proyecten tantas expectativas en torno a la vivienda, al "hogar, dulce hogar". Si realmente deseamos disfrutar de una salud plena y contribuir a la mejora ambiental, debemos empezar por nuestro hogar, para que nuestra vivienda sea realmente ese espacio vital que nos proteja y nos aporte el mínimo de comodidad y de calidad de vida que resulta básico e imprescindible ${ }^{12}$.

El tipo de discurso, oral o escrito, es una variable de la investigación.

La audición programada en cada recogida de material es únicamente de grabaciones de hombres o de mujeres, lo que convierte la "voz evaluada" (hombre o mujer) en una variable más del estudio. En atención a la técnica de pares falsos empleada, se han mezclado para la audición las grabaciones de los distintos hablantes, tanto las orales como las de lectura, manteniendo, en la progresión de escucha, la alternancia entre grabación oral y grabación de lectura. Los informantes oyen, seguidas, pues, voces de hablantes de distinta procedencia, alternando discurso oral y lectura.

10 Aprovechamos la ocasión para agradecer a todos los hablantes que han producido las grabaciones utilizadas, y a los investigadores que nos las han proporcionado, su valiosísima colaboración desinteresada en el proyecto.

11 Hemos querido, con ello, darle continuidad a la iniciativa de López Morales (1979) y hacer posible la comparación de resultados.

12 El texto ha sido proporcionado por María Sancho, que lo utilizó en su estudio sobre las actitudes de inmigrantes ecuatorianos en Madrid (Sancho Pascual 2014). 


\subsubsection{Realización del cuestionario}

Por último, la entrevista presenta, como herramienta fundamental de obtención de datos, la realización de un cuestionario, de preguntas directas e indirectas, abiertas y cerradas y, en su mayoría, con escalas de diferencial semántico, con el que se pretende obtener información sobre percepciones y valoraciones de los informantes hacia las variedades del español y, con ello, sobre las actitudes previsibles hacia las mismas. Se cumplimenta para cada una de las voces escuchadas, y, como explicamos a continuación, consta de diferentes secciones.

\subsubsection{El cuestionario ${ }^{13}$}

Con objeto de conocer las creencias y las actitudes de personas de distintos colectivos, hispanohablantes y no hispanohablantes, hacia las ocho variedades normativas del español, hemos elaborado un cuestionario específico que proporciona información sobre la valoración de los informantes y sus percepciones y pareceres, tanto de manera directa como indirecta, a través de escalas de intensidad con diferencial semántico, preguntas cerradas con alternativas fijas y preguntas abiertas.

El cuestionario está compuesto por 12 preguntas y, como hemos mencionado con anterioridad, se contesta para cada una de las voces escuchadas. Al comienzo, además, antes de activar la primera grabación, se responde a una pregunta general abierta: En su opinión, ¿dónde se habla mejor el español?

13 Para medir la consistencia interna del cuestionario elaborado y determinar su confiabilidad, esto es, el grado en que produce resultados coherentes y consistentes, hemos aplicado el coeficiente alfa de Cronbach para instrumentos de respuesta escalar. El valor máximo de este coeficiente es 1 , el valor mínimo aceptable es 0.7 y los valores entre 0.7 y 0.9 indican una buena consistencia interna del instrumento (Celina y Campo-Arias, 2005: 577). Los datos estadísticos de esta prueba de confiabilidad han sido los siguientes:

\section{Estadísticos de fiabilidad}

\begin{tabular}{|c|c|c|}
\hline Alfa de Cronbach & $\begin{array}{c}\text { Alfa de Cronbach basada en } \\
\text { los elementos tipificados }\end{array}$ & N de elementos \\
\hline, 789 &, 807 & 28 \\
\hline
\end{tabular}




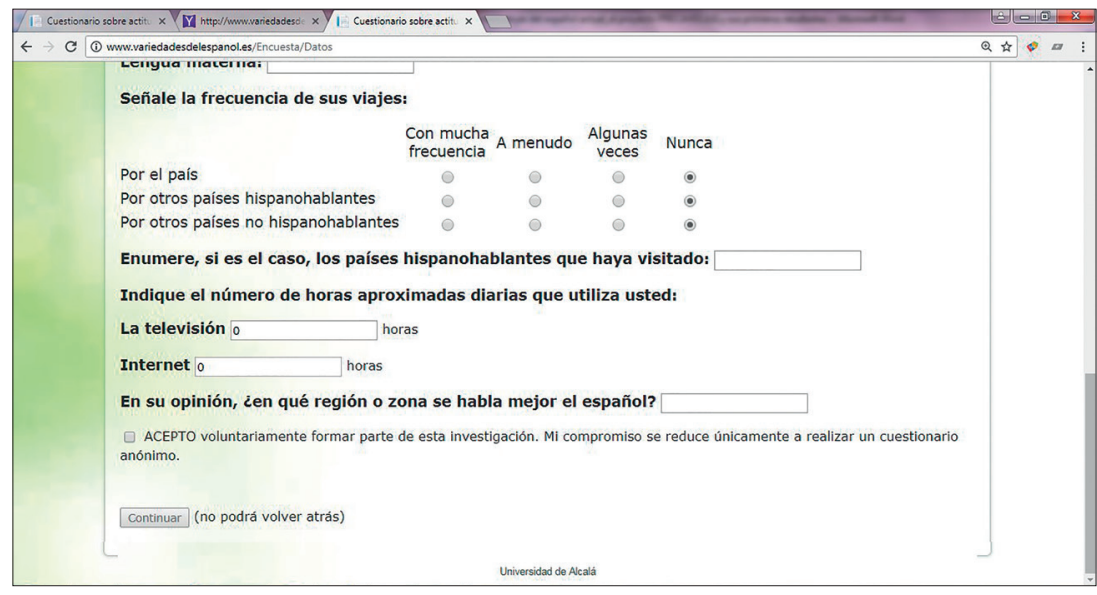

Figura 6. Pregunta directa inicial

Las preguntas giran en torno a tres dimensiones diferentes: valoración directa de la variedad que escuchan, valoración de la variedad a través de la persona que habla o lee y valoración de la variedad a través de la zona geográfica y de la cultura. Por tanto, se trata de dos fuentes de información indirectas y de una directa.

\section{1) Valoración directa de la variedad}

El primer bloque de preguntas nos sirve para conocer la valoración del informante sobre la variedad que oye, así como su percepción sobre la proximidad entre tal variedad y la propia, de manera que obtengamos también datos sobre la valoración de la variedad vernácula. Para ello, se comienza pidiendo al informante que valore cada variedad a través de una escala de intensidad, preestablecida con 6 grados, formada por adjetivos opuestos que hacen referencia a características relacionadas con el conocimiento (5 características) o con la afectividad (6 características). En concreto, trabajamos con los pares bipolares siguientes: áspera/suave, monótona/ variada, rural/urbana, lenta/rápida, confusa/clara; desagradable/agradable, complicada/sencilla, distante/cercana, dura/blanda, aburrida/divertida, fea/ bonita. Hemos optado por una escala de 6 grados, es decir, una escala par en la que no existe el término neutro en la puntuación, con objeto de hacer que el informante se incline hacia el polo positivo o el negativo en relación con la variedad. Y para evitar respuestas automáticas, además, se han mezclado las características de las dimensiones cognoscitiva y afectiva, y se ha variado el orden de colocación en los polos de las características positivas y negativas. 


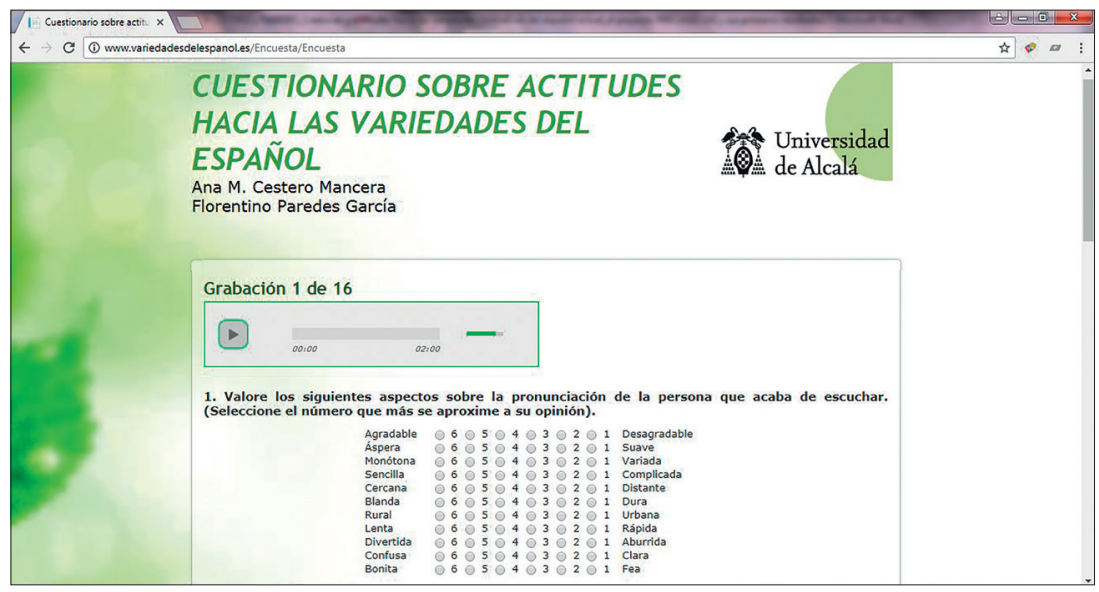

Figura 7. Cuestionario: valoración directa de la variedad

A continuación, se pide al informante que mencione los aspectos de la pronunciación escuchada que le hayan gustado especialmente y los que le hayan disgustado, lo que nos permite conocer cuáles son los fenómenos lingüísticos valorados positiva o negativamente de la variedad, y que indique su consideración sobre la proximidad entre su pronunciación y la escuchada, con lo que obtenemos información sobre la valoración de su propia variedad y las creencias sobre la distancia entre variedades diatópicas.

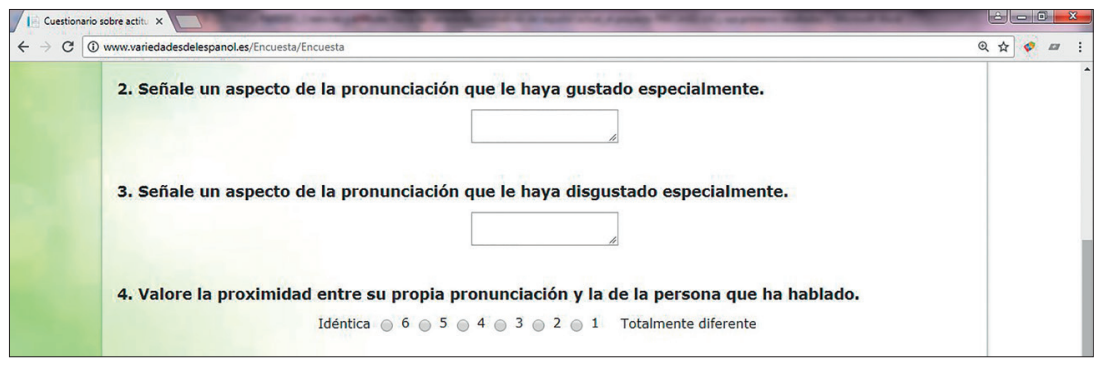

Figura 8. Cuestionario: otras preguntas para obtener valoración directa de la variedad

2) Valoración de la variedad a través de consideraciones sobre la persona que habla

El segundo bloque de preguntas está diseñado para obtener información que complemente los datos recogidos con el primer conjunto de preguntas de forma indirecta. En esta ocasión, se pide a los informantes que emitan 
su opinión sobre la persona que habla, bajo el convencimiento de que, en realidad, valoran la variedad que oyen, que asocian a rasgos psicológicos y sociales determinados, lo que tendrá incidencia, sin lugar a dudas, en el prestigio y en la dirección de la variación, así como en su difusión.

En esta parte del cuestionario, se realizan tres preguntas cerradas (que contienen, en las opciones establecidas, valoración graduada) y una en forma de escala de diferencial semántico. Las preguntas cerradas piden la opinión del informante acerca del puesto de trabajo, del nivel de ingresos y del nivel de estudios que considera que tiene la persona que está hablando. Con la pregunta de escala de diferencial semántico se solicita que el informante valore, en una gradación de 1 a 6 , características personales de la persona que escucha: inteligencia, simpatía, cercanía, erudición y educación.

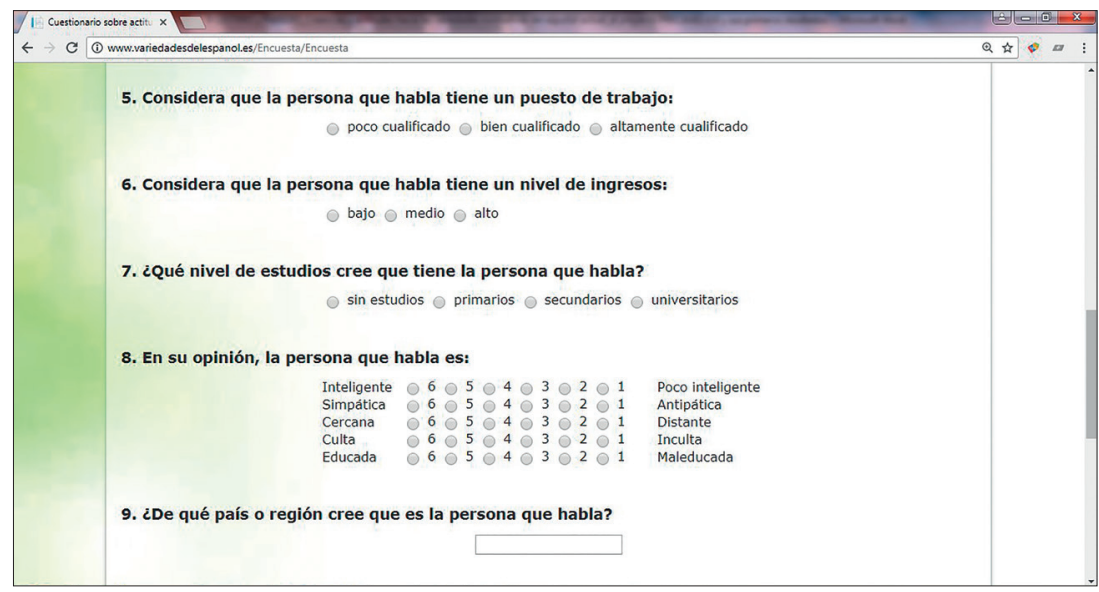

Figura 9. Cuestionario: valoración de la variedad a través de consideraciones sobre la persona que habla

3) Valoración de la variedad a través de consideraciones sobre la región o el país, y la cultura

El tercer y último bloque de preguntas está destinado a conocer, de forma indirecta, consideraciones y valoraciones de los informantes que complementen las anteriores y permitan perfilar las actitudes que muestran; en este caso, se formulan preguntas abiertas y de escalas de diferencial semántico sobre el país, la zona o región de la persona que habla y sobre su cultura.

La primera pregunta requiere que el informante diga si conoce a personas del país o la variedad de procedencia del hablante (de la audición) y que, si es así, exponga brevemente la opinión que le merecen. 
Las dos últimas cuestiones requieren que el informante valore, de nuevo en una escala de 1 a 6 , el país o la zona de la que cree que es la persona que ha escuchado (retrasado/avanzado, aburrido/divertido, extraño/familiar, feo/ bonito) y su cultura (tradicional/innovadora, pobre/rica, distante/cercana, poco interesante/muy interesante). En ambos casos, se han seleccionado características que requieren conocimiento y que no lo requieren, con objeto de cubrir tanto la dimensión cognoscitiva como la afectiva de las creencias y actitudes.

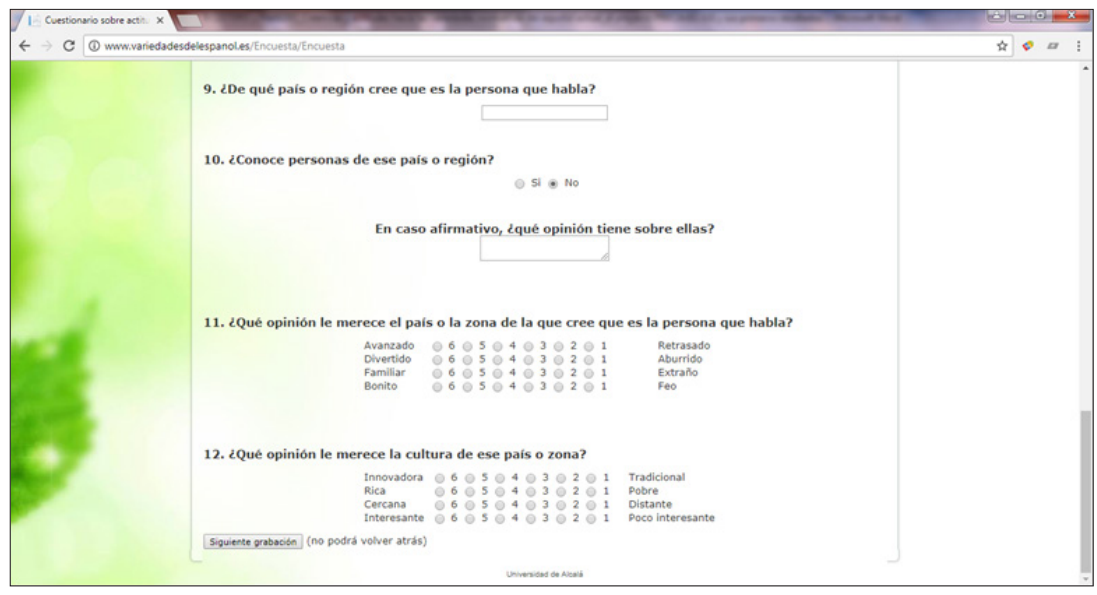

Figura 10. Cuestionario: valoración de la variedad a través de consideraciones sobre la región o el país, y la cultura

\subsection{LA MEDICIÓN DE CREENCIAS Y ACTITUDES:} TRATAMIENTO Y ANÁLISIS DE LOS DATOS

En el Proyecto para el estudio de creencias y actitudes hacia variedades del español en el siglo XXI, hemos decidido comenzar con el estudio coordinado de creencias y actitudes de determinados colectivos que consideramos influyentes en las direcciones de prestigios sociolingüísticos, así como en la enseñanza y la adquisición de lenguas segundas y extranjeras. Por ello, en la primera etapa, de la que da buena cuenta este volumen monográfico, hemos recogido encuestas de personas pertenecientes a los siguientes grupos o colectivos:

1) estudiantes de Filología o Lingüística que no han cursado asignaturas relacionadas con la sociolingüística o la dialectología (esto es, sin conocimientos básicos sobre variedades del español), 
2) estudiantes de Filología o Lingüística que han cursado asignaturas relacionadas con la sociolingüística o la dialectología (es decir, con conocimientos básicos sobre variedades del español),

3) estudiantes de otras carreras, y que, por tanto, no tienen conocimientos básicos sobre variedades del español y, además, no se interesan, conscientemente, por la lengua y su uso, y

4) profesores de español como lengua extranjera (ELE), profesionales que deberían tener conocimiento sobre variedades del español y tienen un papel determinante en la consideración "exterior" del español y sus variedades.

Como hemos mencionado previamente en varias ocasiones, PRECAVES XXI está siendo llevado a cabo por un equipo de investigadores de distintas zonas normativas del español que trabajamos de manera coordinada. Los investigadores se ocupan de recoger y estudiar el material de su zona geolectal, así como de ofrecer los resultados y las explicaciones oportunas al respecto, en atención a los objetivos de investigación que se van proponiendo en el proyecto. En España, sobre la zona centro-norte peninsular trabajan Ana M. Cestero y Florentino Paredes; además, José Ramón Gómez Molina y Cristina Villalba, Cristina Illamola y Beatriz Méndez se ocupan de comunidades bilingües: la valenciana, la catalana y la balear respectivamente; la zona andaluza está a cargo de Inmaculada Santos y Antonio Ávila (Málaga), Antonio Manjón-Cabeza (Granada) y Juana Santana (Sevilla); el área de la variedad canaria es estudiada por Clara Hernández y Marta Samper. En cuanto a Hispanoamérica, la zona mexicana y centroamericana la atiende Dinorah Pesqueira, Ana M. González Mafud e Irania Malaver se centran en el Caribe, Claudia González y su equipo trabajan con la zona andina, Abelardo San Martín y Silvana Guerrero investigan el área chilena, y, por último, Claudia Borzi y Sofía Gutiérrez hacen lo propio con la variedad rioplatense.

En la primera parte del proyecto, de la que constituyen una muestra destacada los artículos de este volumen, se propuso trabajar sobre tres aspectos concretos:

- El prestigio de las variedades normativas del español

- La percepción y valoración de la variedad propia

- La identificación y valoración del resto de variedades normativas del español 
Para ello, se formularon las siguientes preguntas de investigación, cuya respuesta, por zonas, se encuentra en los artículos que componen el monográfico:

1) ¿Para los sujetos estudiados (del área normativa con la que se trabaja) existe alguna variedad de español que pueda considerarse mejor o más prestigiosa?

2) ¿Qué percepción tienen los sujetos estudiados de su propia variedad (cómo la valoran)?

3) ¿En qué medida los sujetos estudiados identifican el resto de variedades cultas del español y cómo las valoran en líneas generales?

La aplicación informática para la obtención de material del proyecto proporciona una tabla en $\operatorname{Excel}^{\circ}$ en la que se vuelcan, codificados y tabulados en parte, los resultados de los cuestionarios cumplimentados en las encuestas organizadas por cada investigador. Trabajamos con una muestra de más de 50 encuestas por colectivo y zona, cuando es posible. Los coordinadores de PRECAVES XXI terminan de codificar de manera manual las tablas y las remiten al investigador correspondiente, quien las recibe preparadas para los análisis. Con los datos tabulados, cada investigador procede a la realización de los análisis cualitativos y cuantitativos pertinentes; se complementan los análisis estadísticos, cuando se considera necesario o conveniente, con algunas pruebas realizadas mediante el programa SPSS, versión 15.0.

Los trabajos recogidos en este volumen dan cuenta de este primer estudio. En una segunda fase del proyecto, que ya hemos comenzado, ampliaremos los colectivos para obtener representación de toda la población (hablantes nativos de español sin especialización en la lengua y representativos de distintos grupos sociales) y, además, estableceremos dos vías de investigación en el marco de la enseñanza y adquisición de español como lengua extranjera: actitudes de docentes y discentes de ELE hacia variedades del español y actitudes de profesores y de estudiantes hacia variedades no nativas; para ello, haremos una recogida complementaria de materiales entrevistando a estudiantes de ELE. 


\section{PERCEPCIÓN DE LAS VARIEDADES CULTAS DEL ESPAÑOL: CREENCIAS Y ACTITUDES DE JÓVENES UNIVERSITARIOS HISPANOHABLANTES}

El presente volumen se organiza en diez capítulos, uno de carácter teóricometodológico, y diez con resultados concretos, cinco de ellos sobre áreas de España y cuatro sobre zonas de Hispanoamérica. El artículo que abre el monográfico, redactado por los coordinadores del proyecto, presenta las bases teóricas y metodológicas del proyecto y ofrece también algunos resultados conjuntos que se derivan de esta fase del PRECAVES XXI. El resto de artículos se dedica a la presentación de los resultados de cada una de las áreas estudiadas: todos ellos llevan un título similar, que solo difiere en el nombre de los sujetos a quienes se ha estudiado y es similar también la estructura, que ha tratado de respetar un esquema común -en todo caso siempre respondiendo a las tres preguntas indicadas-, si bien, como es lógico cada investigador ha tenido libertad en la exposición de sus resultados. De este modo, el segundo artículo, redactado por Ana M. Cestero y Florentino Paredes, se dedica a las creencias y actitudes de los universitarios del centro-norte peninsular (especialmente de Madrid). El siguiente, que firma Beatriz Méndez, estudia los datos de los mallorquines. Las encuestas recogidas y analizadas por Juana Santana, que firma el cuarto trabajo, contienen los resultados de los sevillanos, como representantes de la Andalucía occidental. Antonio Manjón-Cabeza, por su parte, ofrece en el quinto trabajo, los datos de los granadinos, completando de este modo la visión de los andaluces, ahora desde el área de la Andalucía oriental. Con el trabajo sobre el área canaria, redactado por Clara Hernández y Marta Samper, se cierra el conjunto de artículos dedicados a las áreas de España. El artículo de M. Claudia González Rátiva y Diana Muñoz, dedicado a las creencias y actitudes de los medellinenses como representantes del área andina, inicia la información que el PRECAVES XXI transmite sobre las áreas hispanoamericanas. La región chilena está representada por el trabajo de Abelardo San Martín y Silvana Guerrero. Y, por último, cierra el volumen el artículo firmado por Claudia Borzi y Sofía Gutiérrez Böhmer, dedicado a los jóvenes universitarios rioplatenses.

En la reunión de coordinación que los equipos del PRECAVES XXI mantuvieron en 2017 en Bogotá, durante el XVIII Congreso Internacional de la ALFAL, se acordó trabajar en cada área con una muestra en torno al centenar de encuestas, como mínimo. Lo resultados que se presentarán en este monográfico proceden de las encuestas realizadas a casi novecientos jóvenes universitarios hispanohablantes, 590 originarios de España y 297 
de Hispanoamérica ${ }^{14}$. La distribución de la muestra analizada es la que se ofrece en la tabla 1.

\begin{tabular}{ll}
\hline Zona & Encuestas \\
\hline Madrid (España) & 204 \\
& \\
Palma de Mallorca (España) & 80 \\
Sevilla (España) & 100 \\
Granada (España) & 89 \\
Las Palmas de Gran Canaria ((España) & 117 \\
Medellín (Colombia) & 108 \\
Santiago (Chile) & 100 \\
Buenos Aires (Argentina) & 89 \\
\hline TOTAL & 887
\end{tabular}

Tabla 1. Encuestas de jóvenes universitarios

En cada zona, como se observará de la lectura de las páginas que siguen, las creencias y actitudes adoptan formas y características específicas particulares En cuanto a los resultados de conjunto más destacables en las investigaciones que se ofrecen en este monográfico pueden señalarse las que se enumeran a continuación.

1. Está muy asentada la creencia de que existe un modelo prestigioso de español. Esta creencia, sostenida por el $60 \%$ de los sujetos aproximadamente, está relacionada con la formación dialectal recibida, de modo que la opinión de que todas las variedades son equivalentes va ascendiendo a medida que sube la formación. No obstante, esta correlación no siempre se mantiene. Algunas muestras incorporan, como se ha dicho, estudiantes que cursan un máster de ELE y resultan especialmente llamativos los porcentajes que en este colectivo alcanza la creencia de que hay lugares donde se habla mejor el español; sirva de ejemplo Madrid, donde asciende al 52,2\%.

14 Lamentablemente no ha sido posible incorporar a este volumen los trabajos relativos al área mexicana y al área caribeña insular, a pesar de que las encuestas en ambos casos ya están realizadas. 


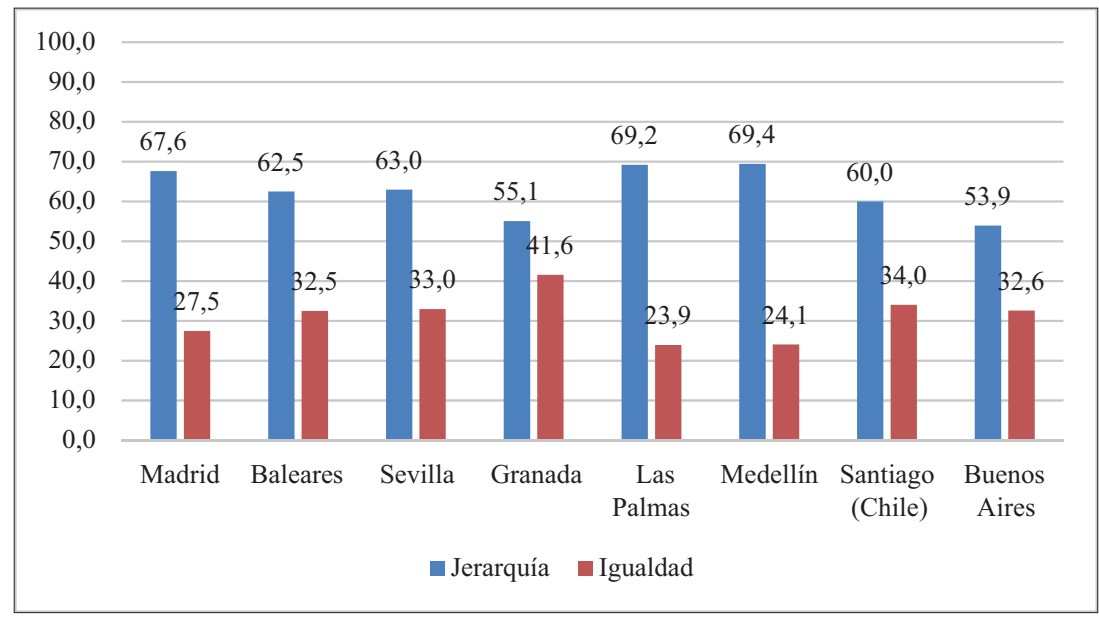

Gráfico 1. Creencias sobre jerarquía o igualdad entre las variedades del español

2. Si se cree que existe una variedad mejor que otra, ¿dónde se sitúa ese modelo de español? Los resultados que ofrece el gráfico 2 muestran ordenados por porcentaje los casos en que los hablantes han citado expresamente su propia variedad como modelo de lengua, es decir, que han dicho que donde mejor se habla es en la zona a la que pertenece el propio hablante ${ }^{15}$.

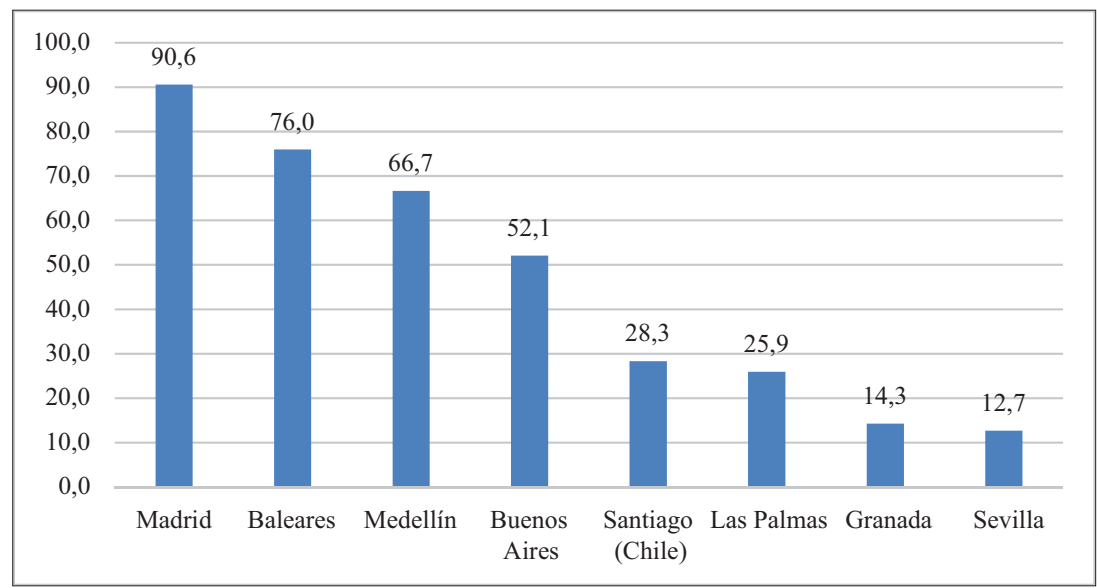

Gráfico 2. Consideración de la variedad propia como modelo de español

15 En este recuento se han descartado tanto la falta de respuesta como las respuestas que señalan la equivalencia entre las variedades. 
Los españoles ocupan las posiciones extremas en el ordenamiento de esta creencia. Los hablantes del centro-norte de España, cuyo dialecto es el castellano, son quienes de manera prácticamente unánime consideran a Castilla como la mejor variedad del español. Esta opinión es compartida también por los baleares, cuya variedad está próxima a la castellana en el plano fónico. En el otro extremo se sitúan los hablantes andaluces (sevillanos y granadinos) y los canarios, conscientes de que sus propias variedades históricamente han carecido de reconocimiento y prestigio abierto. Entre los hispanoamericanos, los colombianos son quienes manifiestan una mayor consideración de la variedad propia como modelo de lengua, mientras que los chilenos se sitúan en el polo opuesto.

3. Independientemente de las creencias sobre el modelo de lengua, los hablantes de cada área identifican y valoran su propia variedad, tanto directa como indirectamente. Es decir, en todos ellos funciona el prestigio de grupo vinculado a la solidaridad (Borrego Nieto 1996: 141). Sistemáticamente se repite una valoración más baja en las escalas del "componente cognitivo".

4. Los datos del PRECAVES XXI permiten conocer también en qué grado los hablantes reconocen los acentos ajenos (gráfico 3).

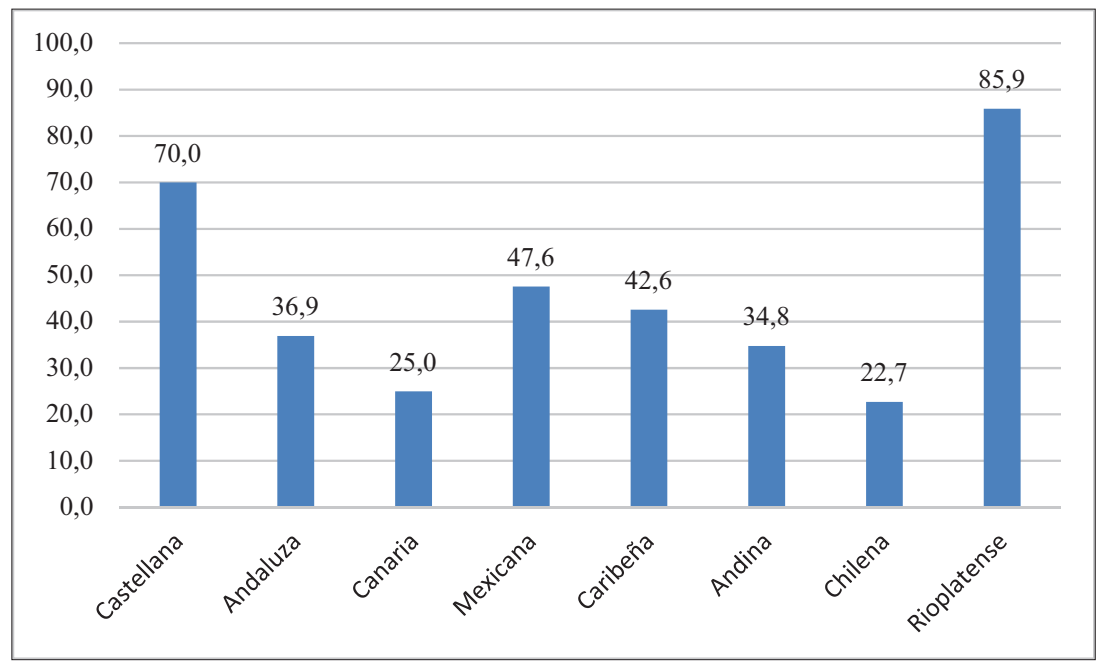

Gráfico 3. Grado de identificación de las variedades (excluida la propia) 
En conjunto, el acento más claramente reconocible para los hablantes de español es el rioplatense, identificado con exactitud el 85,9\% de las veces que es escuchado. El castellano es el segundo acento mejor reconocido, con el 70,0\% de aciertos en su identificación, aunque se sitúa a más de quince puntos porcentuales del primero ${ }^{16}$. Estas dos son las únicas, además, que son identificadas en más de la mitad de las ocasiones en que son oídas; en todos los demás casos, es superior el número de ocasiones en que los evaluadores se equivocan respecto al territorio al que corresponden o bien que solo son capaces de dar una indicación aproximada respecto al origen del locutor. En posiciones intermedias en cuanto al grado de identificación por otros hablantes se sitúan las variedades mexicana, caribeña, andaluza y, algo más retrasada, la andina. Las variedades que obtienen un porcentaje más bajo en cuanto al reconocimiento del acento son la variedad chilena y la canaria; llama la atención, en este sentido, que ambas son a menudo confundidas entre sí. Si hubiera que encontrar una explicación a este bajo grado de reconocimiento, habría que buscarla en la ausencia de rasgos claramente identificadores de estas variedades, especialmente en el plano fónico, además de la posición periférica que ambas variedades ocupan dentro de sus respectivos territorios, el canario en España y el chileno en América.

¿Coinciden los españoles y los americanos en la identificación de los dialectos? Las similitudes y disimilitudes se pueden observar en el gráfico 4.

16 Hay que tener en cuenta que se considera solo las respuestas en las que se identificó con exactitud el acento escuchado. Pero no se puede obviar que para muchos hablantes, especialmente los americanos, el dialecto castellano se identifica prototípicamente con la variedad hablada en España. Así pues, el porcentaje subiría notablemente si se considerasen los casos de identificación aproximada (es decir, la respuesta "España"): paradigmático es lo que sucede en las encuestas de Buenos Aires, donde la identificación exacta del acento castellano alcanza solo el 5,62\%, pero asciende al $90,45 \%$ si se consideran los casos de identificación aproximada. 


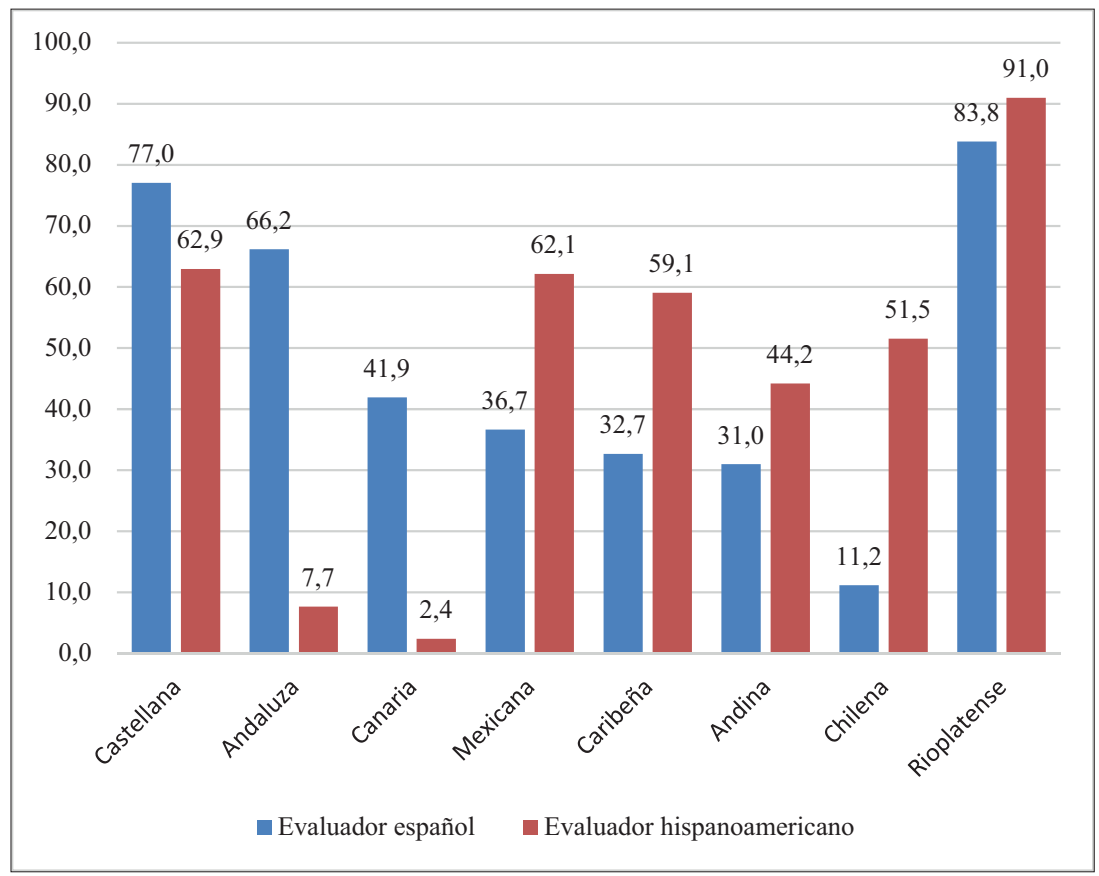

Gráfico 4. Grado de identificación de las variedades (excluida la propia) según el origen del evaluador

La variedad reconocida de modo similar por los hablantes de las dos orillas es la rioplatense, aunque es algo mejor identificada por los evaluadores americanos. En el resto, las diferencias son más notorias y, además, se repite idéntica pauta: los españoles identifican y discriminan mejor los acentos españoles y los hispanoamericanos se muestran más capaces para identificar los americanos. Las variedades andaluza y canaria no se identifican prácticamente nunca con exactitud por parte de los americanos, y la variedad chilena resulta difícilmente identificable para los españoles.

5. Por último, en este repaso rápido de resultados conjuntos del proyecto PRECAVES XXI, destaca la puntuación que obtienen todas las variedades del español en la valoración directa e indirecta. Los jóvenes hispanohablantes evalúan de manera positiva las variedades cultas del español, independientemente del geolecto al que representen. 


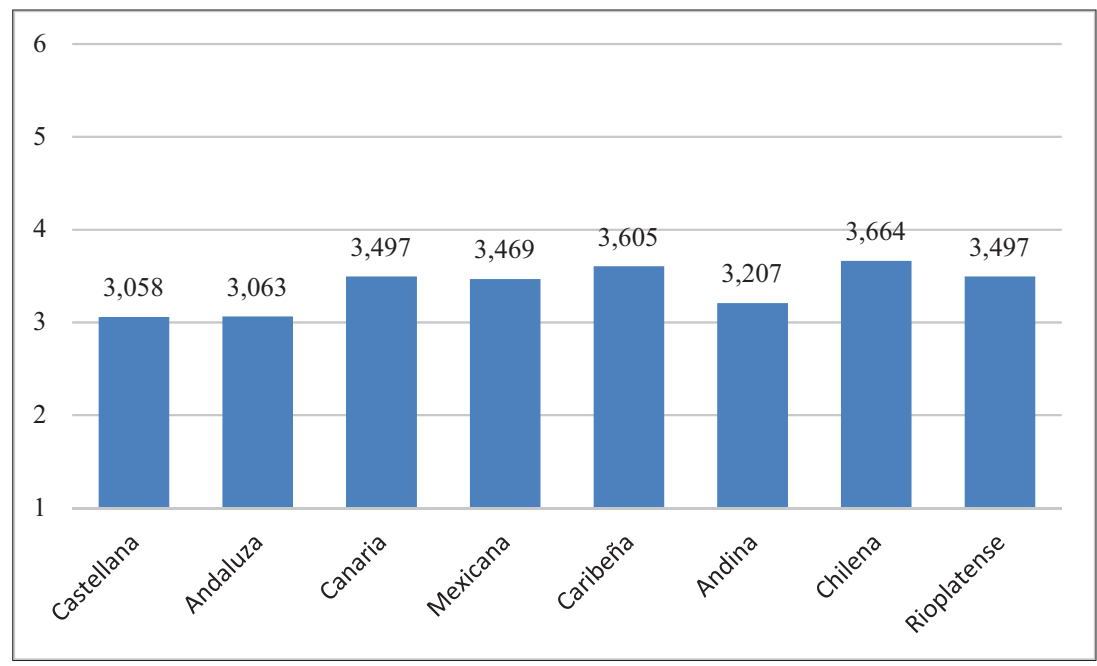

Gráfico 5. Valoración directa de las variedades (excluida la propia)

La valoración directa media de las variedades cultas (gráfico 5) se sitúa en todos los casos por encima del 3. La variedad mejor evaluada es la chilena, frente a lo que sucedía en el caso de la identificación, donde, como se ha visto, ocupaba la última posición y se convertía en la menos reconocible. Similar es el caso del canario, también con un bajo grado de identificación, pero una valoración directa alta. Esto indica que el reconocimiento del acento y la valoración de la variedad no corren en paralelo: al contrario, los datos avalan la hipótesis de que las variedades menos reconocibles - esto es, menos marcadas- se perciben como más neutras y, precisamente por ello, reciben una alta calificación. Argumento en contra de esta hipótesis, sin embargo, lo constituye la alta valoración del acento rioplatense, de rasgos lingüísticos muy reconocibles.

Entre las variedades que reciben una puntuación más baja se encuentran la castellana y la andina, además de la andaluza, todas ellas con claras marcas diferenciadoras por rasgos fónicos, gramaticales o léxicos (cf. Moreno Fernández 2009). No deja de llamar la atención la presencia de las dos primeras, ya que a menudo ambas se citan entre los modelos más prestigiosos de la lengua española en los respectivos continentes. 


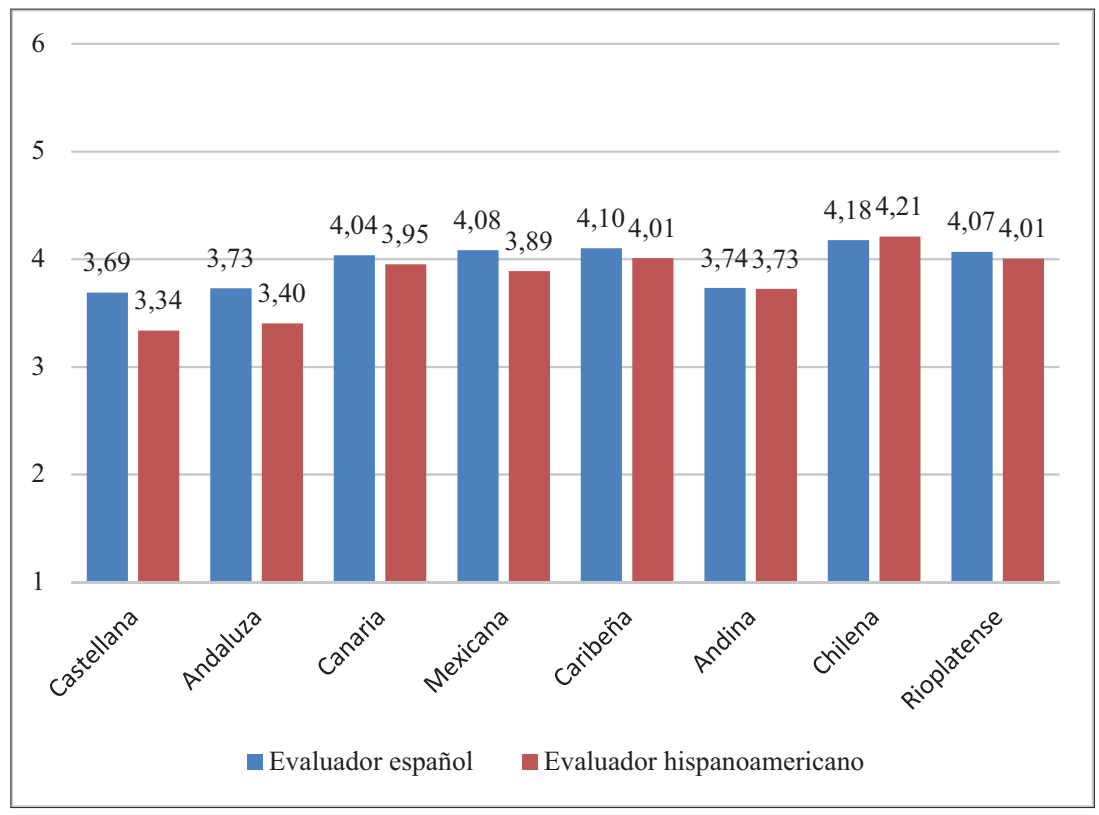

Gráfico 6. Valoración directa de las variedades (excluida la propia) según el origen del evaluador

Por último, la valoración directa que reciben las variedades según si el evaluador es americano o europeo se ofrece en el gráfico 6, a partir de cuyos datos hay que destacar varios hechos. En primer lugar, la evaluación positiva que reciben todas las variedades, independientemente del origen del evaluador: la calificación se sitúa siempre por encima del 3,5, con la salvedad de las variedades castellana y andaluza, calificadas por los evaluadores americanos algunas décimas por debajo de ese nivel. Destacable también es que los españoles puntúen las variedades por encima de los hispanoamericanos -la única excepción en este punto es el dialecto chileno-, si bien las diferencias nunca son demasiado acusadas. En tercer lugar, y como cierre, la evaluación directa de las variedades sigue las pautas descritas en el párrafo anterior.

En definitiva, como se ha podido ver, los resultados del proyecto PRECAVES XXI permiten obtener una visión coherente y sistemática de las creencias acerca de las variedades cultas del español y las actitudes hacia ellas, que pone de relieve un alto grado de coincidencia entre los hispanohablantes en la evaluación positiva de la diversidad de acentos español. Muchos otros detalles y precisiones a lo expuesto se podrán encontrar en los textos que siguen. 


\section{REFERENCIAS BIBLIOGRÁFICAS}

Agueyisi, Rebecca y Joshua Fishman. 1970. Language attitudes Studies. A Brief Survey of Methodological Approaches. Anthropological Linguistics 12: 137-157.

AJzen, IceK. 1988. Attitudes, Personality and Behaviour. Milton Keynes: O.U.P.

Allport, Gordon W. 1935. Attitudes. En C. Murchinson (ed.). A Handbook of Social Psychology. Worcester: Clark University Press. [Reproducido en M. Fishbein (ed.) (1967). Readings in Attitude Theory and Measurement, pp. 1-38. New York: John Wiley and Sons].

Alvar López, Manuel. 1972. Niveles socio-culturales en el habla de Las Palmas de Gran Canaria. Las Palmas: Excmo. Cabildo Insular.

1981. Español, castellano, lenguas indígenas (Actitudes lingüísticas en Guatemala sudoccidental). Logos Semantikós. Studia Linguistica in honorem E. Coseriu (1921-1981), pp. 393-406. Madrid: Gredos. Disponible en http://www.cervantesvirtual.com/servlet/ SirveObras/p184/12260629778115974198846/p0000001.htm\#I_0 [Consulta: 11/2013].

1983. Español en Santo Domingo y Español de España. Análisis de algunas actitudes lingüísticas. Lingüistica española actual 2: 225-239. Disponible en http://www. cervantesvirtual.com/servlet/SirveObras/p184/02450529767823832976613/index.htm [Consulta: 11/2013].

1986a. Hombre, etnia, estado. Actitudes lingüisticas en Hispanoamérica. Madrid: Gredos.

1986b. Cuestiones de bilingüismo y diglosia en el español. El castellano actual en las comunidades bilingües de España, pp. 11-48. Salamanca: Junta de Castilla y León. Disponible en http://www.cervantesvirtual.com/servlet/SirveObras/ p184/8914951098125836434379/p0000001.htm\#I_0 [Consulta: 11/2013].

Alvar López, Manuel y Antonio Quilis. 1984. Reacciones de unos hablantes cubanos ante diversas variedades del español. Lingüistica Española Actual VI: 229-265.

Borrego Nieto, Julio. 1996. Leonés. En M. Alvar (dir.). Manual de dialectología hispánica. El Español de España, pp. 139-158. Barcelona: Ariel.

Buzón García, José M., M. a Begoña Gómez Devís y José R. Gómez Molina. 2017. Actitudes lingüisticas en Valencia y su área metropolitana. Estudio longitudinal y análisis de tendencias. Valencia: Tirant Humanidades.

Castellanos, Isabel M. 1980. Actitudes sociolingüísticas hacia el español del Caribe. Lenguaje Cali 11: 73-91.

Celina, Heidi y Adalberto Campo-Arias. 2005. Aproximación al uso del coeficiente alfa de Cronbach. Revista colombiana de psiquiatría XXXIV / 4: 572-580. Disponible en http:// www.redalyc.org/pdf/806/80634409.pdf [Consulta: 01/2014].

Cestero Mancera, Ana María y Florentino Paredes García. 2015. Creencias y actitudes hacia las variedades normativas del español actual: primeros resultados del Proyecto PRECAVES-XXI. Spanish in Context, volumen 12, número 2: 255-279.

Chiquito, Ana Beatriz y Miguel Ángel Quesada Pacheco (eds.). 2014. Actitudes lingüisticas de los hispanohablantes hacia el idioma español y sus variantes. Bergen: University of Bergen (Colección: Bergen Language and Linguistics Studies (BeLLS), 5. Formato: Electrónico).

Cobo de Gambier, Nancy. 2011. Creencias y actitudes sociolingüisticas en la clase universitaria de E/LE en Alemania. Tesis para optar al grado de Doctora en Lingüística aplicada a la enseñanza del español como lengua extranjera en la Universidad Antonio de Nebrija. 
Cohen, Andrew D. 1974. Mexican-American evaluational judgments about language varieties. Linguistics 136: 33-51.

Cooper, Robert. L. y Joshua A. Fishman (eds.). 1974. Language Attitudes I. International Journal of the Sociology of Language 3.

1974. The study of language attitudes. International Journal of the Sociology of Language 3: 5-19.

(eds.) 1975. Language Attitudes II. International Journal of the Sociology of Language 5.

Corvalán, Grazziella y Germán de Granda (eds.). 1982. Sociedad y lengua. Bilingüismo en el Paraguay. Madrid: CPES.

De la Zerda Flores, Nancy y Robert Hopper. 1975. Mexican american's evaluations of spoken Spanish and English. Speech Monographs 42: 91-98.

Etxebarria Arostegui, Maitena. 1995. El bilingüismo en el Estado Español. Bilbao: Ediciones FBV.

Fishbein, Martin. 1965. A Consideration of Beliefs, Attitudes and Their Relationship. En R. Steiner y M. Fishbein (eds.). Current Studies in Social Psychology, pp. 107-120. Nueva York: Holt, Rinehart \& Winston.

Gardner, Robert. C. 1982. Language Attitudes and Language Learning. En E. Ryan y H. Giles (eds.). Attitudes towards Language Variation, pp. 132-147. London: Arnold Publishers. 1985. Social Psichology and Second Language Learning. London: Arnold Publishers.

Giles, Howard y Ellen B. Ryan. 1982. Attitudes towards Language Variation. Londres: Arnold Publishers.

Gimeno Menéndez, Francisco. 1986. Sustitución lingüística en las comunidades de habla alicantinas. ELUA. Estudios de Lingüística 3: 237-267.

Gómez Molina, José R. 1998. Actitudes lingüisticas en una comunidad bilingüe y multilectal. Área metropolitana de Valencia. Cuadernos de Filología. Anexo XXVIII. València: Universitat de València.

2002. Lenguas en contacto y actitudes lingüísticas en la comunidad valenciana. En J. L. Blas y otros (eds.). Estudios sobre lengua y sociedad, pp. 53-86. Castellón: Publicaciones de la UJI.

Lambert, Wallace E. 1964. Social Psycholgy. Englewood Cliffs, Newy Jersey: Prentice Hall. 1967. A Social Psychology of Bilingualism. Journal of Social Issues 23: 91-108.

Lambert, Wallace E., R. C. Gardner, R. Olton y K. Tunstall. 1968. A Study of the roles of attitudes and motivation in second-language learning. En J. A. Fishman (ed.). Readings in the Sociology of Language, pp. 473-491. The Hague: Mouton.

Lambert, Wallace. E., R. C. Hodgson, C. Gardner y S. Fillenbaum. 1960. Evaluative reactions to spoken language. Journal of Abnormal and Social Psychology 60: 44-51.

Lamíquiz IbáÑez, Vidal y Pedro Carbonero Cano. 1987. Perfil sociolingüístico del sevillano culto. Sevilla: Universidad de Sevilla.

LASAGABASTER, DAVID. 2007. Language use and language attitudes in the Basque Country. En D. Lasagabaster y A. Huguet (eds.). Multilingualism in European Bilingual Contexts. Language Use and Attitudes, pp. 65-89. Clevedon: Multilingual Matters.

Lope Blanch, Juan M. 1968. El español de América. Madrid: Ediciones Alcalá. 1972a. Estudios sobre el español de México. México: UNAM.

1972b. El concepto de prestigio y la norma lingüística del español. Anuario de Letras X: 29-46.

1986. El estudio del español hablado culto: historia de un proyecto. México: UNAM. 
López Morales, Humberto. 1979. Dialectología y sociolingüística. Temas puertorriqueños. Madrid: Hispanova.

1983. Estratificación social del español de San Juan de Puerto Rico. México: Universidad Nacional Autónoma de México. 1989. Sociolingüística. Madrid: Gredos.

2001. Actitudes lingüísticas hacia el bable en la ciudad de Oviedo. Lingüística Española Actual 23/2: 145-158.

Martín Butragueño, Pedro. 2014. Fonología variable del español de México. Volumen I: procesos segmentales. México: El Colegio de México.

Martínez, María D. y JuAn A. Moya. 2000. Reacciones actitudinales hacia la variación dialectal en hablantes granadinos. Revista Española de Lingüística 23/2: 137-160.

Martín Zorraquino, M. Antonia. 1995. Estudio sociolingüístico de la Franja Oriental de Aragón. Aragón: Gobierno de Aragón y Universidad de Zaragoza.

Moreno FernándeZ, Francisco. 1992. Norma y prestigio en el español de América. Apuntes para una planificación de la lengua española. Revista de Filología Española LXXII: 345-359.

(ed.). 1993. La división dialectal del español de América. Alcalá de Henares: Servicio de Publicaciones de la Universidad de Alcalá.

1996. Metodología del 'Proyecto para el estudio sociolingüístico del Español de España y de América' (PRESEEA). Lingüística 8: 257-287.

2000. Qué español enseñar. Barcelona: Arco/Libros.

2005. Principios de sociolingüística y sociología del lenguaje. 2. edición. Barcelona: Ariel.

2009. La lengua española en su geografia. Madrid: Arco/Libros.

2012. Sociolingüística cognitiva. Proposiciones, escolios y debates. Madrid/ Frankfurt: Iberoamericana/Vervuert.

Moreno Fernández, Francisco y Juliana Moreno Fernández. 2004. Percepción de las variedades lingüísticas de español por parte de hablantes de Madrid. Lingüistica Española Actual XXVI/1: 5-38.

Moreno Fernández, Francisco y Jaime Otero Roth. 2007. Atlas de la lengua española en el mundo. Barcelona: Ariel / Fundación Telefónica / Instituto Cervantes.

Ortega Ojeda, Gonzalo. 1981. El español hablado en Canarias: visión sociolingüística. Revista de Filología de la Universidad de la Laguna 0: 111-116.

Osgood, Charles E., George J. Succi y Percy H. Tannenbaum. 1957. The Measurement of Meaning. Chicago: University of Illinois Press. [Traducción española de 1976. La medida del significado. Madrid: Gredos].

Pitarch, Vicent. 1983. Un cas singular del conflicto lingüístic: la situació actual del País Valencià. Treballs de Sociolingüistica Catalana 5: 41-51.

PRESEEA. 2008. Marcas y etiquetas mínimas obligatorias, Versión 1.0. 31-01-2008. Disponible en http://www.linguas.net/preseea.

Preston, Dennis R. 1989. Perceptual Dialectology. Dordrecht: Foris.

1999. Handbook of Perceptual Dialectology. Amsterdam: John Benjamins.

2003. Language with an attitude. En J. K. Chambers, Peter Trudgill y Natallie Schilling-Estes (eds.). The Handbook of Language Variation and Change, pp. 40-66. Malden: Blackwell.

Prikhodkine, Alexei y Dennis R. Preston (eds.). 2015. Responses to Language Varieties: Variability, Processes and Outcomes. Amsterdam: John Benjamins.

Quilis, Antonio. 1983. Actitud de los ecuatoguineanos ante su lengua. Lingüística Española Actual V: 269-310. 
Quintanilla, José Roberto A. 2012. Esbozo de un estudio de actitudes lingüísticas en El Salvador. Revista Española de Lingüística 42/1: 175-195.

Rubín, JoAn. 1968. National Bilingualism in Paraguay. La Haya: Mounton.

SANCHO PAScual, María. 2014. Integración sociolingüistica de los inmigrantes ecuatorianos en Madrid. Alcalá de Henares: Servicio de Publicaciones de la Universidad de Alcalá.

Sanz Huéscar, Gema. 2008. Actitudes lingüísticas de los inmigrantes rumanos en Alcalá de Henares. Trabajo de Investigación Tutelado inédito. Alcalá de Henares: Universidad de Alcalá.

2010. Actitudes lingüísticas. Rumanos en Alcalá. Lengua y migración 2/2: 97-111.

Shuy, Robert y Ralph W. Fasold (eds.). 1973. Language attitudes: Current Trends and Prospects. Washington: Georgetown University Press.

Williams, Frederick. 1973. Some research notes on dialect attitudes and stereotypes. En R. W. Shuy y R. W. Fasold (eds.). Language attitudes: Current Trends and Prospects, pp. 113-128. Washington: Georgetown University Press

1974. The Identification of Linguistic Attitudes. International Journal of the Sociology of Language 3: 21-32. 